\title{
Immunogenicity of Inactivated Vaccine against Rhinopneumonia, Salmonella Abortion and Horse Strangles
}

\author{
M.P. Neustroev ${ }^{1,2}$, K.P. Yurov ${ }^{3}$, S.V. Alexeyenkova ${ }^{3}$, N.P. Tarabukina ${ }^{1}$, S.G. Petrova ${ }^{1}$ \\ ${ }^{1}$ Federal State Budgetary Scientific Institution Yakut Scientific Research Institute of Agriculture named after M.G. \\ Safronov, Laboratory of Veterinary Biotechnology and Laboratory for the Development of Microbial Preparations, \\ Scientific-Production Center "Hotu-Bact" Ltd., 677001, Republic of Sakha (Yakutia), Yakutsk, Bestuzheva-Marlinskovo, \\ Str.23/1 \\ ${ }^{2}$ Yakut State Agricultural Academy, Sergelyakh highway 3km, 3, Yakutsk, Republic of Sakha (Yakutia), 677007, Yakutia \\ ${ }^{3}$ Federal State Budgetary Scientific Institution All-Russian Scientific Research Institute of Experimental Veterinary \\ Medicine named after Kovalenko Y.R., Federal Agency of Scientific Organizations of Russia, Laboratory of Virology and \\ Reference Laboratory of the International Epizootic Bureau for Rhinopneumonia and Dourine of Horses, 109428, \\ Moscow, Ryazansky Avenue, 24/1
}

\begin{abstract}
The aim of the work is to assess the immunogenicity of inactivated associated vaccine against rhinopneumonia, salmonella abortion and horse strangles. Methods: A laboratory test was performed on BALB/c mice aged 10-14 days weighing 5-7 grams and outbred white mice weighing 18-20 grams. An experimental vaccine series was used, a culture fluid (fugate) of the bacterial strain Bacillus subtilis TNP-3 was used as the immunomodulator. Two series of experiments were carried out. The level of antibodies was determined in ELISA. To evaluate the immunogenic properties of the preparation against rhinopneumonia, a control virus was administered with the adapted horse rhinopneumonia virus at a dose of $0,02 \times 6,0 \mathrm{lg}$ TCD50/ml intracerebrally 14 days after the primary and 14 days after the second vaccination. To assess the immunogenic properties of the preparation against salmonella abortion, infection with virulent strains in a lethal dose was administered subcutaneously 14 days after vaccination. The effectiveness of immunization was determined by the number of mice resistant to morbidity and mortality to infection, as well as by the change in mass in comparison with animals of negative $(n=4)$ and positive $(n=9)$ control groups. Repeated vaccination of the vaccine with an interval of 14 days provided on average 1,5-2 fold antibody growth. A two-fold vaccination of the vaccine protected $88,8 \%$ of the lethal outcome. Infection with virulent strains of salmonella and strangles streptococcus among the immunized mice did not cause disease and mortality. Consequently, the vaccine has antigenic activity that provides the synthesis of specific antibodies, and is characterized by a sufficiently high immunogenic activity.

Key words immunogenicity, vaccine, rhinopneumonia, salmonella abortion, horse strangles.
\end{abstract}

\section{INTRODUCTION:}

The prevention of some common infectious diseases of horses, including rhinopneumonia (viral abortion of horses), salmonella abortion, and horse strangles, remains an unresolved problem in the Republic of Kazakhstan, in the Russian Federation, primarily of horse herd breeding [1, 2]. As a result of losses from these diseases, the yield of foals decreases by $100 \%$ to $45 \%$ [3, $4]$.

According to the veterinary service of the Republic of Sakha (Yakutia) and our studies in 2002-2016, outbreaks of horse rhinopneumonia were recorded in 96 locations in 15 districts, and salmonella abortion in 139 locations in 20 districts.

The significant spread of infectious abortions in recent years is largely due to the insufficiency of routine diagnostic studies, the lack or low effectiveness of vaccine prevention; uncontrolled delivery of horses of breeds from other regions of Russia and the exchange between different regions of the republic, extreme conditions of winter pasture, peculiarities of conducting the industry (the concentration of a significant number of horses during the weaning of foals), a decrease in natural resistance in the winter-spring period, a prolonged persistence of pathogens in permafrost conditions of Eastern Siberia [5, 6].

The system of anti-epizootic measures against rhinopneumonia developed for horse farms in the European part of the Russian Federation, under the conditions of horse herd in Yakutia showed insufficient effectiveness, in particular due to the certain reactogenicity of the viral vaccine [13]. Based on this, we developed a harmless and immunogenic inactivated vaccine against rhinopneumonia. We evaluated it for immunogenicity and harmlessness on laboratory animals. It was established its effectiveness in the conditions of disadvantaged farms [7, 8]. In 2010-2012 we have developed, tested and approved by the Rosselkhoznadzor an inactivated vaccine against salmonella abortion of horses. Currently, the preparation is used in the subjects of the Russian Federation and Kazakhstan.

An inactivated vaccine against horse strangles was proposed in 2000. Due to the expiry of the validity period of the permits, the vaccine is not produced. Currently, epizootically topical strains of streptococcus are isolated, promising for the development of a new vaccine. Vaccines against horse strangles, salmonella abortion and rhinopneumonia have been developed in the Republic of Kazakhstan, which are introduced separately. These vaccines are not registered in the Russian Federation $[3,4]$.

As the results of our studies indicate, rhinopneumonia in the condition of herd horse maintenance is recorded as a mixed viral-bacterial infection. In addition, about 20-30 \% of the mares are carriers of a horse strangles streptococcus, thereby serving as sources of infection for 
foals, in which the horse strangles is often observed as a mixed infection with rhinopneumonia, salmonellosis [913]. The virus of the rhinopneumonia possesses immunosuppressive properties and aggravates the course of salmonellosis and horse strangles. At the same time, the mortality rate can reach $22 \%$. [13].

According to our data, the canonical schemes of anti-epizootic measures for rhinopneumonia, salmonellosis or horse strangles, including vaccination of commercial vaccines, do not provide the necessary effect in horse farms in the Northern regions of Eastern Siberia for a number of reasons:

- a double vaccination of the viral vaccine is a negative factor in the conditions of Yakutia, since the second administration of the vaccine falls on January-February, the most difficult period in terms of climatic conditions. The bringing of herds at this time is extremely undesirable due to the laboriousness and danger of abortion of a traumatic nature;

- vaccination of the viral vaccine is undesirable due to low air temperature to minus $43-50{ }^{\circ} \mathrm{C}$, dysbacteriosis of the gastrointestinal tract in horses; deficiency of fodder by protein and mineral-vitamin components;

- the immunization period against the rhinopneumonia, salmonella abortion and horse strangles coincides with vaccination against anthrax. Therefore, it is impossible to combine vaccination of different vaccines in the period after weaning foals.

Thus, the development of vaccines against viralbacterial infections, including effective immunomodulators, remains topical. Moreover, there are no analogues of the associated vaccines against salmonella abortion, rhinopneumonia and horse strangles.

The aim of the study is to evaluate, using the laboratory model, the immunogenicity of the experimental associated vaccine inactivated with the immunomodulator against rhinopneumonia, salmonella abortion and horse strangles.

\section{MATERIALS AND METHODS:}

A laboratory test of the associated vaccine against rhinopneumonia, salmonella abortion and horse strangles was performed in mice of the BALB/c line aged 10-14 days weighing 5-7 grams in the Laboratory of Virology of the All-Russian Institute of Experimental Veterinary Medicine and on outbred white mice weighing 18-20 grams in the Laboratory for Developing Microbial Preparations of the Yakut Scientific Research Institute of Agriculture.

An experimental series of inactivated associated vaccine against rhinopneumonia, salmonella abortion and horse strangles (Yakut Scientific Research Institute of Agriculture, All-Russian Scientific Research Institute of Experimental Veterinary Medicine) was used, a culture fluid (fugate) of the bacterial strain Bacillus subtilis TNP-3 was used as an immunomodulator [7].
BALB/c and outbred mice were obtained from the "Stolbovaya" laboratory animal farm in the Moscow Region.

A neurotropic strain "P1/1" of the horse's rhinopneumonia virus [8] adapted to growth in mice aged less than 40 days was used as a "piercer", as well as a strain of bacteria Sal. abortus equi "BN-12" and strain of bacteria Str. equi "N-5/1", after preliminary determination of lethality.

Two series of experiments were carried out. In the first, 5 groups were formed. Mice of the first group $(n=9)$ were injected once subcutaneously in a volume of $0,3 \mathrm{ml}$, II $(\mathrm{n}=8)$ - 2-fold, 0,3 $\mathrm{ml}$ subcutaneously at intervals of 14 doses, mice III and IV groups $(n=22)$ were not vaccinated and were subsequently used for negative and positive controls during experimental infection with the rhinopneumonia virus.

In the second series of experiments, four groups were formed: mice of I and II groups $(n=10)$ received a vaccine at a dose of $0,3 \mathrm{ml}$, animals of groups III and IV $(n=20)$ were not vaccinated and were subsequently used for negative and positive controls on experimental infection with virulent strains of pathogens of salmonella abortion and horse strangles.

During the entire observation period, a clinical examination of the mice of the control and test groups was carried out every 2-3 days after vaccination and the change in their weight was recorded.

To assess the antigenic activity of the vaccine, blood was taken from the tail vein 14 days after the initial vaccination and 14 days after the second vaccine and also from all control animals. The level of antibodies was determined in ELISA. To assess the immunogenic properties of the preparation against rhinopneumonia, a control virus infection was administered with the adapted horse rhinopneumonia virus at a dose of $0,02 \times 6,0 \mathrm{lg}$ $\mathrm{TCD}_{50} / \mathrm{ml}$ intracerebrally 14 days after the primary and 14 days after the second vaccination. To assess the immunogenic properties of the preparation against salmonella abortion and horse strangles, infection with virulent strains with sub-titrated lethal doses was administered subcutaneously 14 days after vaccination. The effectiveness of immunization was determined by the number of mice resistant to morbidity and mortality to infection, as well as by the change in mass in comparison with animals negative $(n=4)$ and positive $(n=9)$ control groups.

\section{RESULTS AND DISCUSSION:}

Subcutaneous administration of a vaccine in a volume of $0,3 \mathrm{ml}$ caused a toxic reaction in linear mice: a decrease in mass, disheveled hair coat, oppression was observed on the 2-3 days after the vaccination. The following days, these signs were leveled (Fig. 1). 


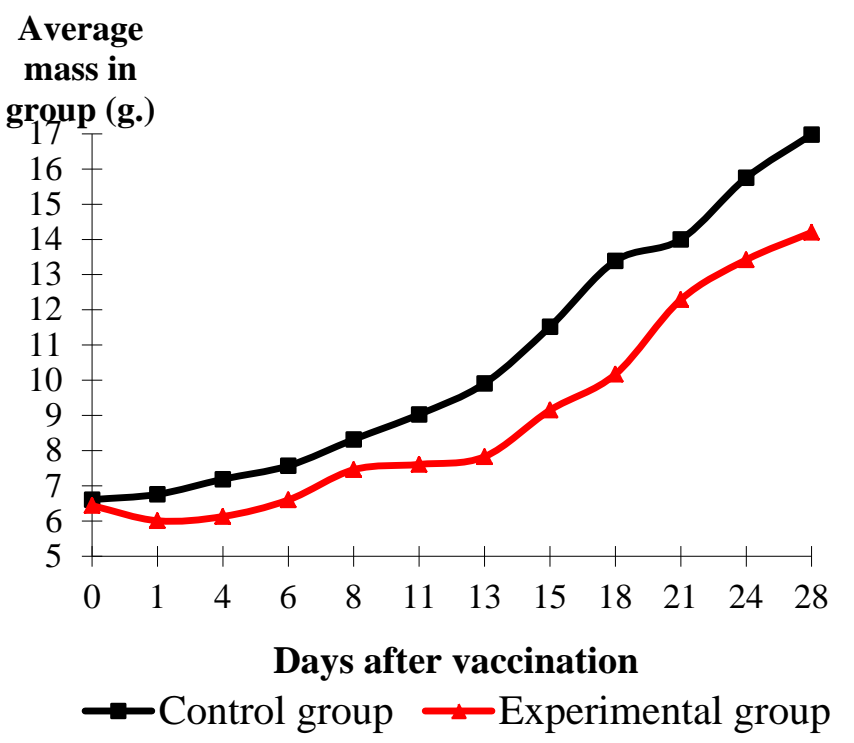

Fig. 1 Assessment of toxicity of preparations with a 2-fold introduction of the vaccine according to the indicator of the change in the mass of mice: 1 - control group, 2 - experimental.

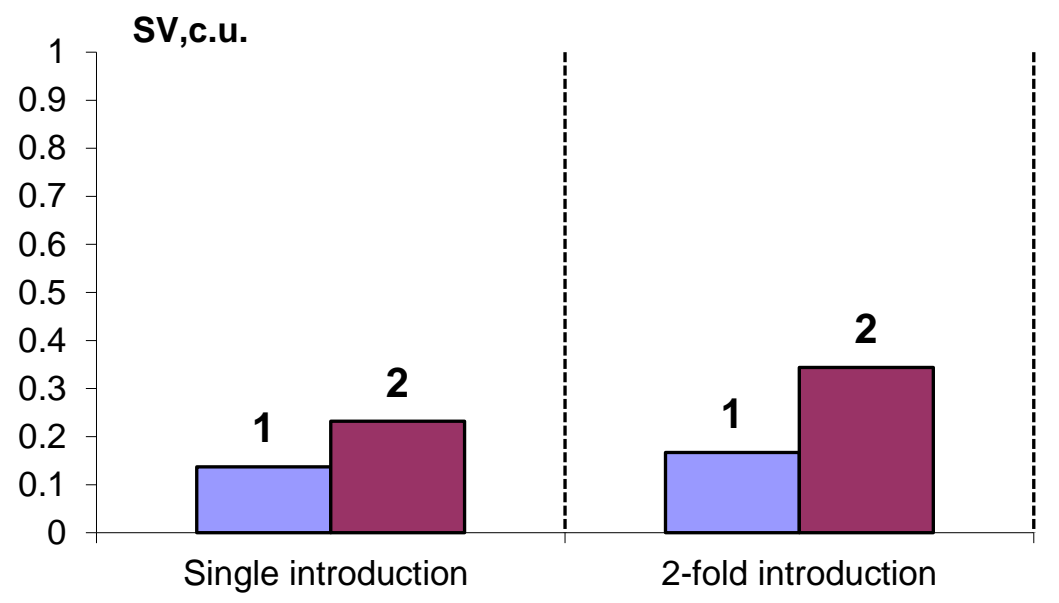

Fig. 2 The level of antibodies to HVH-1 in control and vaccinated mice (ELISA serum dilution 1:400): 1st column control group, 2nd - experimental

$\%$

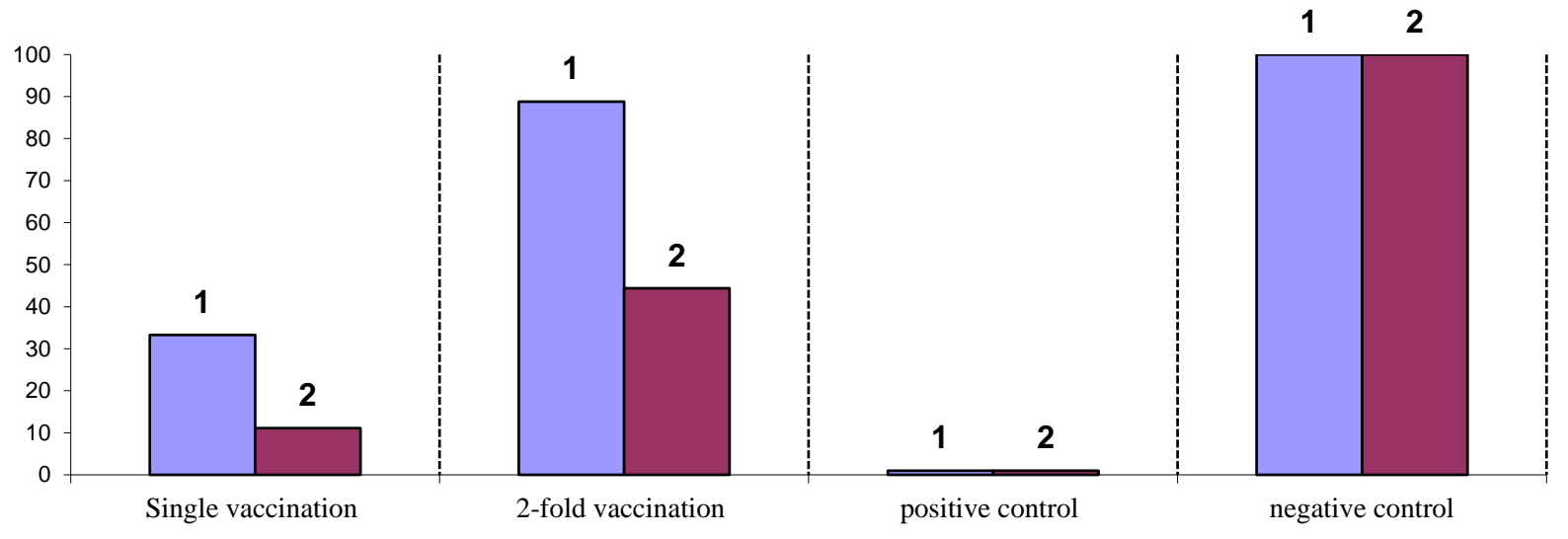

Fig. 3. Immunogenicity of the vaccine against rhinopneumonia for mice according to the results of the control infection: the first column - protection against death, the second - from the disease. 
A single introduction of the vaccine caused the formation of antibodies to HVH-1(herpes virus of horses 1 type) in the diagnostic titer in mice. In this case, repeated introduction of the vaccine with an interval of 14 days provided an average of 1,5-2 fold antibody growth. Consequently, the vaccine has antigenic activity that provides the synthesis of specific antibodies (Figure 2).

The following results were obtained in the experiments with control infection:

- the test vaccine with a single administration has a reactogenicity for mice; the protective effect of the experimental infection of $\mathrm{HVH}-1$ on morbidity and lethality with a single injection of the vaccine is $11,1 \%$ and 33,3\%, respectively;

- repeated introduction of the vaccine provided an increase in immunity and protected $88,8 \%$ of the death (Figure 3);

- after infection with a virulent strain of Sal. abortus equi $\mathrm{BN}-12$, the disease and mortality were not marked among the immunized mice; in the control group, after the injection of the causative agent out of 10, all fell ill and 8 died;

- infection of vaccinated mice with a virulent strain of a horse strangles streptococcus did not cause disease of all mice, in the group of non-immunized mice all fell ill and 6 (60\%) died.

In previous laboratory tests of the immunogenicity of the inactivated vaccine against rhinopneumonia, it was established that the protective effect of experimental infection of HVH-1 on the incidence of linear mice in single and double-entry vaccine is $60 \%$, on lethality - with a single and double injection of the vaccine - $100 \%$ [8].

Immunization of pregnant mares in November (the period of weaning foals) by inactivated vaccine causes the production of specific hemagglutinizing antibodies in high titers, stimulates immunobiological reactivity (increase of phagocytic, bactericidal and lysozyme activity, content of $\beta$-globulin fraction of protein and lymphocytes). As a result, immunity develops relatively high tension and it increases the business yield of foals.

The inactivated vaccine against rhinopneumonia with a culture fluid of the bacterial strain Bacillus subtilis TNP-3 with single administration is not inferior in effectiveness to live viral vaccine.

Immunization of pregnant mares in disadvantaged settlements by rinopneumonia increases the business yield of foals by $10,9 \ldots 33,3 \%$ [7].

Laboratory monitoring of immunogenicity in linear and outbred white mice of an experimental sample of vaccine inactivated against rhinopneumonia and salmonella abortion was carried out. Associated divalent vaccine prevents from experimental infection with the virus of rinopneumonia $87,5 \%$, and from the injection of the causative agent of salmonella abortion - $100 \%$ of immunized animals. The relatively high immunogenicity of the inactivated vaccine against rhinopneumonia and salmonella abortion is due to the antigenic activity of vaccine strains that provides the synthesis of specific antibodies in high titers and an immunomodulating component that stimulates the immunobiological reactivity of the organism [14].

It should be noted that monovalent vaccine against rhinopneumonia and divalent vaccine against rhinopneumonia and salmonella abortion have a low reactivity for linear mice, which manifests itself in a decrease in the live weight of vaccines compared to control groups.

The trivalent vaccine against rhinopneumonia, salmonella abortion and horse strangles, containing an additional inactivated horse strangles of streptococcus has increased toxicity on linear mice at the age of 2 weeks, which negatively affects the immunity to the rhinopneumonia virus. On outbred mice at the age of 2-3 months toxicity of vaccines was not shown. Bacterial components of the vaccine have a toxic effect on linear mice, and as a result, further control techniques need to be improved by optimizing the dosage of the preparation and the vaccination schedule.

The high efficiency of the inactivated trivalent associated vaccine, in our opinion, can be explained by the antigenic activity of the vaccine strains and the immunomodulating component - the culture fluid (fugate) of the bacterial strain Bacillus subtilis TNP-3, which, according to our previous studies, can induce interferon synthesis and stimulate the immunobiological reactivity of the organism, strengthen immunogenicity of inactivated bacterial and viral vaccines $[15,16]$.

Thus, the inactivated vaccine against rhinopneumonia, salmonella abortion and horse strangles with the culture liquid of the bacterial strain Bacillus subtilis TNP-3, is characterized by a sufficiently high immunogenic activity when tested on laboratory mice.

\section{REFERENCES:}

1. Gulyukin, M.I., Yurov, K.P. Prevention of mass infectious diseases of horses in horse breeding. Veterinary and Nutrition J. 2004, 4, 22-24.

2. Yurov, K.P. Some results of the work of the Laboratory of Virology of All-Russian Scientific Research Institute of Experimental Veterinary Medicine. Veterinary and Nutrition J. 2014, 5, 60-61.

3. Sansyzbay, A.R., Yurov, K.P., Kirikbaev, S.T., Ryabinnikova, A.I., Yarynbaev, M.B. Serological monitoring of horse herpesvirus in Kazakhstan. Materials of the VI Intern. Veterinary Congress (Sochi, 12-15 April 2016). pp.170-174, 2016.

4. Sultakov, A.A., Musaeva, A., Egorova, N.N., Dosanova, A.K. Diagnosis and prevention of salmonella abortion of mares. International Journal of Applied and Fundamental Research. 2015, 12, 1883-1887.

5. Neustroev, M.P. Viral diseases of horses in Yakutia. Agroindustrial Complex of Siberia, Mongolia and the Republic of Kazakhstan in the 21st century: Materials of IV International scientific-practical conf. (Ulan-Bator, 9-10 July 2001). - Novosibirsk, pp.331-332, 2001.

6. Neustroev, M.P., Yurov, K.P. New means and methods of preventing infectious diseases of horse herds. Reports of the Russian Academy of Agricultural Sciences. 2006, 1, 54-56.

7. Neustroev, M.P., Petrova, S.G., Tikhonova, F.M., Baishev, A.A., Yurov, K.P. The test results of inactivated vaccines against rhinopneumonia in production conditions. Achievements of science and technology of agroindustrial complex. 2013, 5, 69-71.

8. Alexeyenkova, S.V., Yurov, G.K., Tkachev, I.Y., Yurov, K.P. Effectiveness of immunization of Balb/c mice with intracerebral infection of herpesvirus of horse type 1. Immunology. Vol.27, 6, pp. 361-363, 2006. 
9. Sweeney C.R., Benson C.E., Whitlock R.H., et all. Description of an epizootic and persistence of Streptococcus equi infections in horses. J. Am Vet. Assoc 1989; 194:1281-1286.

10. Newton J.R., Verheyen K., Talbot N.C., et all. Control of stragless outbreaks by isolation of guttural pouch carriers identified using PCR and culture of Stretococcus equi. Equin Vet. J. 2000;32:515526.

11. Verheyen K., Newton J.R., Talbot N.C., et all. Elimination of guttural pouch infection and inflammation in asymptomatic carriers of Stretococcus equi. Equin . Vet. J. 2000; 32:527-532.

12. Boyle A.G., Rankin S.C., Duffee L., Boston R.S., Wheeler-Aceto H. Streptococcus equi Delection Polymerase Chain Reaction Assay for Equin Nasopharyngeal and Gutural Pouch Wash Samples. J. of Vet. Intern. Med. 2016; 30:276-281.

13. Neustroev, M.P. Horse strangles in Yakutia. - Novosibirsk, 2000, 144 p.
14. Neustroev, M.P., Yurov, K.P., Alexeyenkova, S.V., Tarabukina, N.P., Petrova, S.G., Baishev, A.A. Results of laboratory monitoring of immunogenicity of inactivated vaccine against rhinopneumonia and salmonella abortion of horses. Russian Agricultural Science. 2016, 4, pp. 74-77.

15. Osmaev, I.A., Yurov, K.P., Neustroev, M.P. Immunomodulating properties of endogenous interferon in calves. Veterinary Medicine. 2007, 1, pp.11-12.

16. Neustroev, M.P., Tarabukina, N.P., Fedorova, M.P. The use of probiotics from strains of Bacillus subtilis in agriculture. Agrarian science to agricultural production of Mongolia, Siberia and Kazakhstan: the collection of scientific reports of XII Intern. scientific-practical. Conf. (Ulan-Bator, 6-7 June 2010). - UlanBator. 2010, Part 2, pp.503-507. 